\title{
Quench Performance of Fermilab High Gradient Quadrupole Short Models for the LHC Interaction Regions
}

\author{
N. Andreev, T. Arkan, R. Bossert, J. Brandt, D. Chichili, J. DiMarco, S. Feher, J. Kerby, \\ M.J. Lamm, P.J. Limon, F. Nobrega, D. Orris, I. Novitski, J.P. Ozelis, T. Peterson, G. Sabbi, \\ P.Schlabach, J.Strait, M.Tartaglia, J.C.Tompkins, S.Yadav, A.V.Zlobin*, FNAL, Batavia, IL \\ S. Caspi, A.D. McInturff, R.M. Scanlan, LBNL, Berkeley, CA \\ A. Ghosh, BNL, Upton, NY
}

\begin{abstract}
Fermilab and LBNL are in the midst of a superconducting magnet $\mathrm{R} \& \mathrm{D}$ program to test and optimize the design of quadrupoles to be used in the LHC Interaction Region inner triplets. The magnets are required to deliver a $215 \mathrm{~T} / \mathrm{m}$ gradient across a $70 \mathrm{~mm}$ aperture. Five quadrupole short models have been fabricated and four of them have been tested. This paper describes the last model design details and reports the results of the magnet quench performance study.
\end{abstract}

\section{INTRODUCTION}

Quadrupole magnets for the LHC inner triplets have to provide a nominal field gradient of 205 and $215 \mathrm{~T} / \mathrm{m}$ (high and low luminosity IRs) in a $70 \mathrm{~mm}$ bore, and to operate in superfluid helium at $1.9 \mathrm{~K}$. The design of these magnets has been developed by the collaboration of Fermilab, BNL and LBNL [1-3].

A series of $2 \mathrm{~m}$ long model magnets (HGQ) is being built now at Fermilab to test and optimize the design and assembly method before proceeding to the construction of a full scale prototype magnet. Three models HGQ01-03 have each been tested in two thermal cycles. Model HGQ05 is currently being tested in a second thermal cycle. This paper reports the design optimization and summarizes quench performance of the HGQ short model magnets.

\section{DESIGN OPTIMIZATION}

Magnet cross-section is shown in Figure 1. It consists of a two-layer $\cos (2 \theta)$ coil made of Rutherford-type cables, stainless steel collar laminations and a cold iron yoke. The details of base-line design have been described elsewhere $[2,3]$.

The training histories for the first three models HGQ01-03 were summarized in [3]. These models demonstrated long and slow training at $4.5 \mathrm{~K}$ and $1.9 \mathrm{~K}$. Short sample limit at $1.9 \mathrm{~K}$ has not been reached.

Work supported by the U.S. Department of Energy.

* E-mail: zlobin@fnal.gov

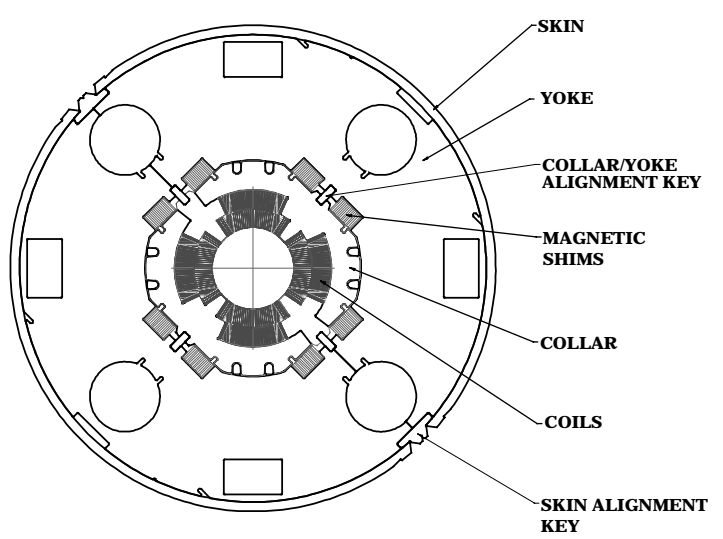

Figure 1: High Gradient Quadrupole cross-section.

Maximum achieved field gradient of $\sim 215 \mathrm{~T} / \mathrm{m}$ is close to the nominal field gradient but it is much lower than the magnet design gradient of $250 \mathrm{~T} / \mathrm{m}$. Significant retraining effect was observed on HGQ03.

Analysis of HGQ01-03 results showed that the observed quench performance was associated with several manufacturing and design details, such as insufficient and non-uniform coil end and end-body transition prestress, low coil end rigidity, a significant difference of thermal contraction for the Ultem spacers and conductor in the coil, longitudinal instability of the collar structure.

Model HGQ05 included a set of changes which addressed the issues raised by previous models. The most important of the changes from the base-line design included on HGQ05 are:

- Use of G10 as end part material

- Re-cure of inner coil at higher pressure, resulting in a higher inner layer elasticity modulus and more uniform inner/outer coil mechanical properties

- A continuous body/end transition, including elimination of key extension

- Welded $75 \mathrm{~mm}$ collar packs with pole filler pieces

- Aluminum end can assemblies over both ends

- Attachment of the end cans to the end plate, which ensures contact between the coil ends and end plates as well as stretches the coil straight section after cooldown 


\section{TEST RESULTS AND DISCUSSION}

All models have been tested at the Fermilab Vertical Magnet Test Facility (VMTF) [4] in normal and superfluid liquid Helium in the temperature range of $1.8 \mathrm{~K}-4.5 \mathrm{~K}$. During the quench performance study about $70 \%$ of the stored energy were extracted and dissipated into external dump resistor. Each model was instrumented with 96 voltage taps installed on the inner and outer coils. Pole turns and turns around wedges were instrumented with four voltage taps each to distinguish between the coil end and straight section quenches.

Coil azimuthal stress and longitudinal end force measurements were made at room temperature during fabrication and during cold test in each excitation cycle. The results for HGQ05 and other models are summarized in Table 1.

Table 1: Mechanical measurement summary

\begin{tabular}{|l|c|c|c|c|}
\hline $\begin{array}{l}\text { Model } \\
\text { number }\end{array}$ & $\begin{array}{c}\text { HGQ } \\
01\end{array}$ & $\begin{array}{c}\text { HGQ } \\
02\end{array}$ & $\begin{array}{c}\text { HGQ } \\
03\end{array}$ & $\begin{array}{c}\text { HGQ } \\
05\end{array}$ \\
\hline $\begin{array}{l}\text { Azimuthal prestress 300K } \\
\text { inner layer, MPa }\end{array}$ & 67 & 73 & 187 & 99 \\
outer layer, MPa & 72 & 94 & 97 & 55 \\
\hline $\begin{array}{l}\text { Azimuthal prestress 1.9K } \\
\text { inner layer, MPa }\end{array}$ & 38 & 76 & 173 & N/A \\
outer layer, MPa & 58 & 84 & 102 & 49 \\
\hline $\begin{array}{l}\text { Azimuthal Lorentz force } \\
\text { inner layer, MPa/kA }\end{array}$ & & & & \\
outer layer, MPa/kA & -0.28 & -0.31 & -0.29 & -0.2 \\
\hline
\end{tabular}

According to the strain gauge data no unloading of the coil was observed up to reached highest operating currents. Coil deformation by Lorentz force was elastic in operation current range.

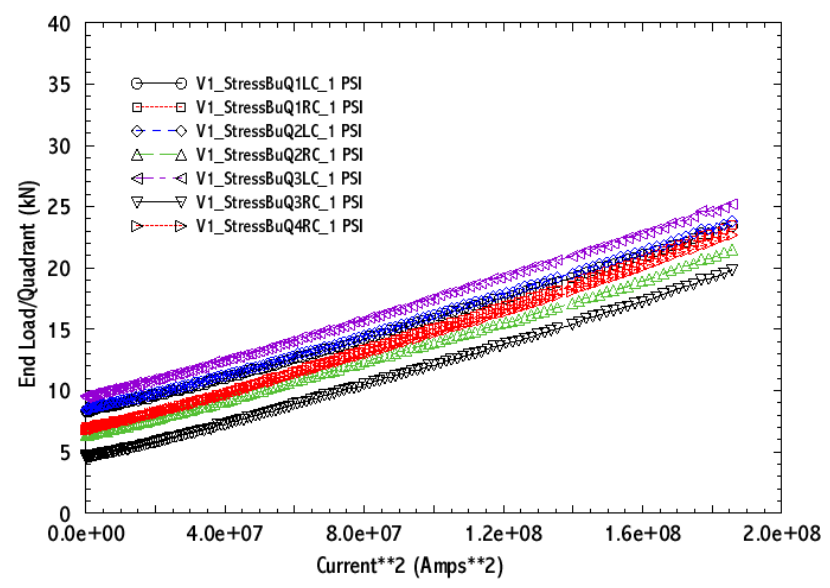

Figure 2: HGQ05 longitudinal Lorentz force.

Figure 2 shows a typical longitudinal coil force measurement for magnet HGQ05. End longitudinal prestress remained on both ends after cooling down. The slope of end force with current represents was about $25 \%$ of the calculated Lorentz force.
Training results for this magnet at $4.5 \mathrm{~K}$ and $1.9 \mathrm{~K}$ in first thermal cycle are presented in Figure 3.

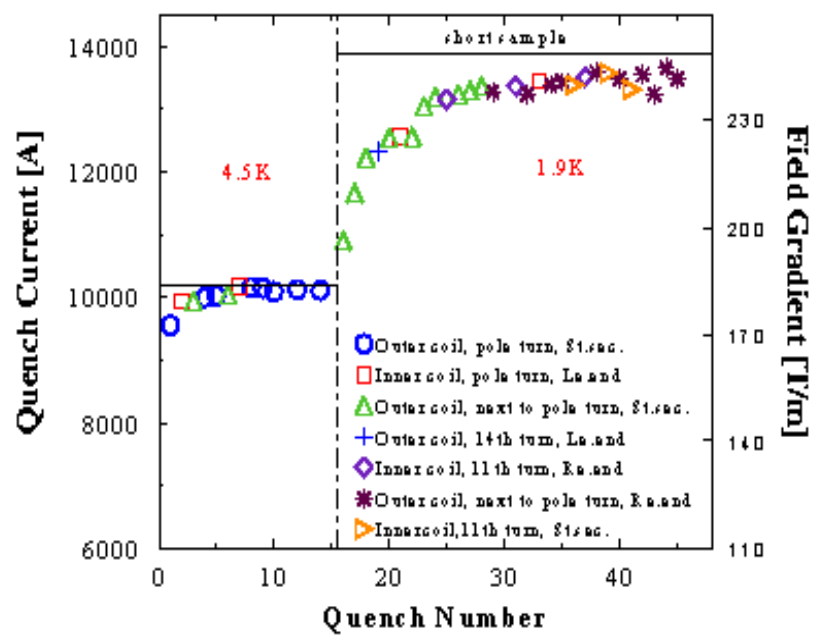

Figure 3: HGQ05 training results at $4.5 \mathrm{~K}$ and $1.9 \mathrm{~K}$.

At $4.5 \mathrm{~K}$ after short training the estimated short sample limit has been achieved. At $1.9 \mathrm{~K}$ only two quenches were required to reach a field gradient of 215 $\mathrm{T} / \mathrm{m}$. When the quench current reached $95 \%$ of the short sample limit the training rate slowed and the erratic quenches occurred in the inner coil turn adjacent to the wedge and in the outer coil return end next to pole turns.

Quench performance in first thermal cycle for the HGQ short models is summarized in Table 2. First quench currents at $4.5 \mathrm{~K}$ and $1.9 \mathrm{~K}$ as well as number of quenches required to reach $11.5 \mathrm{kA}$ are presented.

Table 2: Quench performance summary

\begin{tabular}{|c|c|c|c|}
\hline $\begin{array}{c}\text { Model } \\
\text { number }\end{array}$ & $\begin{array}{c}\text { Iq1(4.5K), } \\
\mathrm{A}\end{array}$ & Iq1(1.9K), A & $\mathrm{N}(11.5 \mathrm{kA})$ \\
\hline HGQ01 & 8776 & 10327 & 8 \\
\hline HGQ02 & 7365 & 9191 & 23 \\
\hline HGQ03 & 7057 & 10019 & 7 \\
\hline HGQ05 & 9553 & 10896 & 2 \\
\hline
\end{tabular}

As it can be seen a dramatic improvement of the magnet training in HGQ05 at both temperatures $4.5 \mathrm{~K}$ and $1.9 \mathrm{~K}$ was observed. The maximum gradient achieved was $\sim 240 \mathrm{~T} / \mathrm{m}$ which is well above the nominal field gradient. The magnet training memory will be studied in the second thermal cycle.

The dependence of quench current with. current ramp rate for HGQ05 at $1.9 \mathrm{~K}$ is shown in Figure 4. One can see two regions on this curve: flat, ramp rate independent region at low current ramp rates and region with monotonic decrease of quench current with the increase of current ramp rate. It was found high ramp rate quenches were determined by $\mathrm{AC}$ losses in the cable near inter layer splices. 


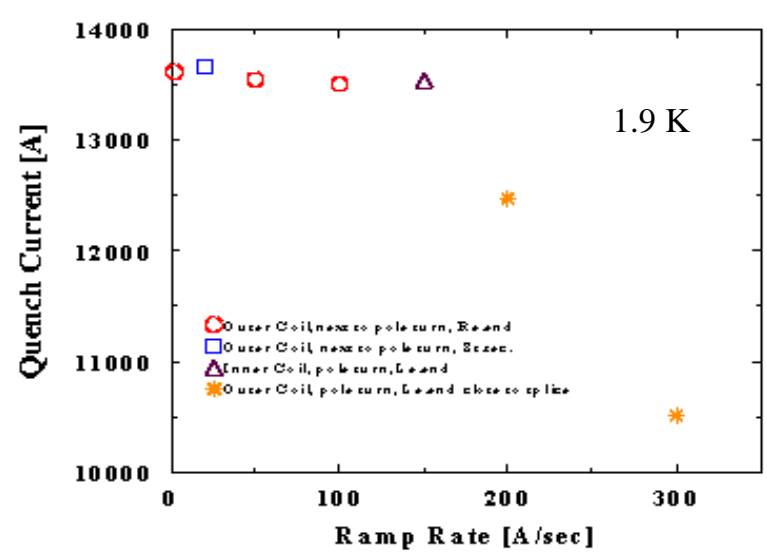

Figure 4: HGQ05 quench current ramp rate dependance.

Summary of magnet ramp rate sensitivity and coil curing temperature is reported in Table 3.

Table 3: Ramp rate sensitivity

\begin{tabular}{|c|c|c|c|}
\hline $\begin{array}{c}\text { Model } \\
\text { number }\end{array}$ & $\begin{array}{c}\text { Coil curing } \\
\text { temperature }\end{array}$ & $\begin{array}{c}\text { Ic(150 A/s), } \\
\text { A }\end{array}$ & $\begin{array}{c}\text { Ic(300 A/s), } \\
\text { A }\end{array}$ \\
\hline HGQ01 & $135^{\circ} \mathrm{C}$ & 11752 & 10965 \\
\hline HGQ02 & $190^{\circ} \mathrm{C}$ & - & 11335 \\
\hline HGQ03 & $195^{\circ} \mathrm{C}$ & 11756 & 11298 \\
\hline HGQ05 & $130^{\circ} \mathrm{C}$ & 13531 & 10519 \\
\hline
\end{tabular}

For all magnets the quench current ramp rate sensitivity was low for current ramp rates up to $300 \mathrm{~A} / \mathrm{s}$. This ramp rate is an order of magnitude higher than the nominal LHC current ramp rate. Quench current did not depend on the coil curing temperature (interstrand resistance in the cable was still quite high). Since the high ramp rate quenches are observed near the inter layer splices, the probable explanation for this ramp rate dependence is the combination of $\mathrm{AC}$ losses and cooling conditions in the solder-filled splice cable.

The dependance of quench current vs. temperature for HGQ05 is presented in Figure 5. This dependence was measured after the completion of magnet test at $1.9 \mathrm{~K}$.

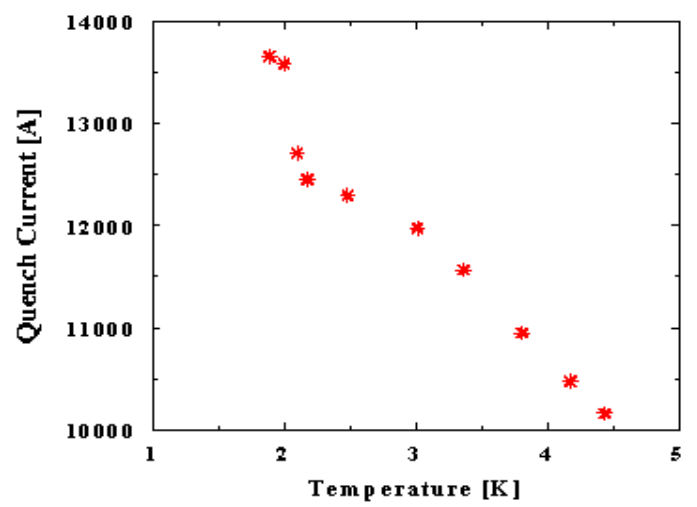

Figure 5: HGQ05 quench current temperature dependance.

The monotonic decrease of quench current with temperature increase was observed at temperatures above $1.9 \mathrm{~K}$. Quenches in the temperature interval 2.2-3.0 K originated in the outer layer coil near one of the inter-layer splices. High resistive heating and restricted cable cooling conditions in splice area can cause a significant reduction of magnet quench current with respect to its short sample limit [5]. Inter-layer splice cooling conditions will be optimized in the next models.

The measured and calculated quench currents at $4.5 \mathrm{~K}$ and $1.9 \mathrm{~K}$ are reported in Table 4.

Table 4: Quench current @ $1.9 \mathrm{~K}$ and $4.5 \mathrm{~K}$

\begin{tabular}{|c|c|c|c|c|}
\hline \multirow{2}{*}{$\begin{array}{c}\text { Model } \\
\text { number }\end{array}$} & \multicolumn{2}{|c|}{ Ic(1.9K), A } & \multicolumn{2}{c|}{ Ic(4.5K), A } \\
\cline { 2 - 5 } & Measured & Calculated & Measured & Calculated \\
\hline HGQ01 & 12.6 & 14.02 & 10.5 & 10.32 \\
\hline HGQ02 & 11.5 & 14.39 & 10.7 & 10.49 \\
\hline HGQ03 & 12.2 & 14.38 & 10.6 & 10.48 \\
\hline HGQ05 & 13.7 & 14.03 & 10.1 & 10.23 \\
\hline
\end{tabular}

After training at $1.9 \mathrm{~K}$ all magnets reached their short sample limit at $4.5 \mathrm{~K}$. With nominal superconductor parameters the temperature margin at nominal operation current for this design is about $2.3 \mathrm{~K}$.

\section{CONCLUSIONS}

Four High Gradient Quadrupole short models have been fabricated and tested at Fermilab. Significant improvement in magnet training at $4.5 \mathrm{~K}$ and $1.9 \mathrm{~K}$ was achieved in last model (HGQ05) as a result of the optimization of design details of magnet support structure. Test of HGQ05 in a second thermal cycle continues. Although the results obtained demonstrate that the magnet design can provide the required quench performance some further optimization is desirable. The short model $R \& D$ program is being re-evaluated based on the program goals and results achieved. Three additional short models are included in the program to complete design optimization.

\section{ACKNOWLEDGMENTS}

Authors would like to thank engineers and technicians of Fermilab Technical Division for the contribution to this work.

\section{REFERENCES}

[1]. R. Bossert et al., "Development of a High Gradient Quadrupole for the LHC Interaction Regions", IEEE Trans. on Applied Superconductivity, Vol. 7, No 2, June 1997, p. 751.

[2]. R. Bossert et al., "Fabrication of the First Short Model of High Gradient Quadrupole for the LHC Interaction Regions", MT-15, Beijing, October 1997.

[3]. R. Bossert et al., "Design, Development and Test of $2 \mathrm{~m}$ Quadrupole Model Magnets for the LHC Inner Triplet", presented at Applied Superconductivity Conference (ASC'98), Palm Desert (CA), September 1998.

[4]. M. J. Lamm et al., "A New Facility to Test Superconducting Accelerator Magnets", PAC'97, Vancouver, Canada, 1997.

[5]. S. Feher et al., "Study of Low- $\beta$ Quadrupole Magnet with Inter-Layer Quench Protection Heaters”, MT-15, Beijing, October 1997. 